\title{
CULTURE AS AN IMPEDIMENT TO SOCIO-ECONOMIC DEVELOPMENT IN HENRY OLE KULET'S BLOSSOMS OF THE SAVANNAH
}

\author{
Violet Nasambu Barasa
}

School of Education, Department of Education Arts, Kabarak University

Cite this article:

Violet Nasambu Barasa (2021), Culture as an Impediment to SocioEconomic Development in Henry Ole Kulet's Blossoms of the Savannah. International Journal of Literature,

Language and Linguistics 4(1), 42-52. DOI:

10.52589/IJLLL-RIYJLL5C.

\section{Manuscript History}

Received: 30 March 2021

Accepted: 5 July 2021

Published: 21 Aug 2021

Copyright $\odot 2020$ The Author(s). This is an Open Access article distributed under the terms of Creative Commons AttributionNonCommercial-NoDerivatives 4.0 International (CC BY-NC-ND 4.0 ), which permits anyone to share, use, reproduce and redistribute in any medium, provided the original author and source are credited.
ABSTRACT: This paper examines how Maasai traditional cultural practices and beliefs in Ole Kulet's novel Blossoms of the Savannah hinder socio-economic development. The cultural practices that incumber socio-economic progress has implication on both the immediate Maasai community (as illustrated through Nasila village) and the society at large. In most societies in Africa, traditional and cultural practices inform and influence the daily experiences and behavior of its people. Early marriages and female genital mutilation are practiced in a number of communities across the African continent in countries such as Kenya, Tanzania, Ethiopia, Guinea among others. One of this communities is the Maasai community in Kenya which is the physical setting of Blossoms of the savannah. Some traditional practices among the Maasai are detrimental as is evident in the long-term impact on the psychological, physical and the general wellbeing of its members. This paper focuses on the intertwinement of early marriages, female genital mutilation (FGM), and patriarchy and how they impact the socio-economic development in the society. Early marriages and female genital mutilation practices are socio-economically retrogressive in a $21^{\text {st }}$ century society. These traditional practices and customs have roots in the social, cultural, economic, historical and political discourse encapsulated within the patriarchal structures and realized through gender inequality. This paper therefore focuses on how the traditional practices impede the realization of development in the Maasai community as advanced in Blossoms of the Savannah.

KEYWORDS: Traditional Cultural Practices, Socio-Economic, Impediment, Development 


\section{INTRODUCTION}

This paper examines how traditional cultural practices among the Maasai community hinder the socio-economic development using illustrations from Ole Kulet's novel Blossoms of the Savannah. I posit that most of these retrogressive traditions and customs are oppressive to the women in the Maasai community as depicted through the female characters. The essay explores a number of traditions and customs such as early marriage, limited education opportunities for girls, female genital mutilation or circumcision, patriarchy, and their effects on the society. In Africa, early marriages and female circumcision has been in existence since time immemorial thereby engraining itself in the daily experiences of a people. Most of these practices are embedded within patriarchal structures and realized through gender inequality. This is based on the fact that girls and boys are not treated equally and therefore socialized differently based on their sex. In Africa, India and some other Asian countries such as Afghanistan, boys are valued and privileged while girls are devalued and viewed as having weaknesses. The gender inequality is, in most cases, entwined with the traditional and cultural practices to naturalize and normalize their occurrence as part of the society's working. In this way, the traditional practices are used to justify why things have to happen the way they do and should therefore not be questioned. Such traditional practices raise the following questions: What is the implication of the traditional and cultural practices on the socio-economic wellbeing of the society? Do these practices work towards progressing the society or toward regressing and stagnating development? The answers to these questions form the bulk of the discussion below.

\section{The Maasai Traditional Cultural Practices: A Socio-economic Regression or Progression?}

Culture is the way of life of a people comprising a totality of features that define them as belonging to a particular grouping and ancestry. In most cases, people who share an identity share other common characteristics such as language, ancestral heritage, traditional practices among other aspects. Such groupings are manifest in form of family, tribe, community, ethnicity, race among other identity markers that make people distinct from the others they interact with. According to Bello (1991), culture is:

[T]he totality of the way of life evolved by a people in their attempts to meet the challenge of living in their environment, which gives order and meaning to their social, political, economic, aesthetic and religious norms thus distinguishing a people from their neighbours. (p. 189)

Accordingly, Aziza (2001) avers that culture is:

[T] he totality of the pattern of behaviour of a particular group of people. It includes everything that makes them distinct from any other group of people for instance, their greeting habits, dressing, social norms and taboos, food, songs and dance patterns, rites of passages from birth, through marriage to death, traditional occupations, religious as well as philosophical beliefs. (p.31)

The quotations above capture the complexity of the sum total of culture. Of note is that cultural practices vary from community to community or region to region. The traditional cultural practices are passed from generation to generation through the socialization process and interactions of its members. This is the case of the Maasai community as advanced in 
Blossoms of the Savannah where the members are socialized in the ways of their community while upholding their culture with zeal. This is well illustrated in the text when the narrative voice tells us that "with trembling teeth and tears welling in his eyes, he [Parsimei Ole Kaelo] swore under his breath that never again in his life, would he ever abandon the culture of his people or live outside his clan (Ole Kulet, p. 40). Accordingly, we are told that the founder of the Maasai culture "had intended that the culture would regulate the lives of the people, and indeed it did. It charted out the way for everyone, from cradle to grave" (Ole Kulet, p.118). In this regard, cultural practices among the Maasai community hold a central position in their lives as it regulates most of their interactions and decisions.

Blossoms of the savannah explores a number of traditional and cultural practices among the Maasai community. The traditional practices, I point out hinder socio-economic development not only to the immediate community but the society at large. Among the Maasai community, cultural practices hold a significant position in the life of the people and cannot be contested. Mama Milanoi in the text observes that in her culture "there was no room for dissent, especially if the subject was in conformity with the culture" (Ole Kulet, p. 61). This observation therefore underscores the place of culture in the lives of the Nasila village of the Maasai community and how the same has to be respected and observed.

Female genital mutilation is one of the cultural practices performed among the Maasais. World health organization (2001) defines female genital mutilation (FGM) as the act that constitutes all procedures which involve the partial or total removal of the external female genitalia whether for cultural or any other non-therapeutic reasons. Female genital mutilation (FGM) is a deeply rooted tradition especially in Masaai community. Though it is revered by the community, it is a setback to socio-economic development as exemplified through its effects on the hapless victims. In most communities that practice FGM, it is seen as a rite of passage from childhood to womanhood. Others value it as a means of preserving a girl's virginity until marriage among other reasons advanced to justify its practice.

In most communities that practice female genital mutilation (FGM) in Africa, it is an important part of the culturally defined gender identity marker. In this case, as gender identity, it explains why most mothers and grandmothers defend the practice. In fact, such women are represented as the custodians of the same. The Maasai community view FGM as a vital part of womanhood, and feel it is necessary for the integration of their daughters into their culture and society. The female genital mutilation in most of these cultures is a precondition for marriage, and marriage is essential to the social life of an individual, community and society at large.

In the Maasai community, women are valued and respected based on having undergone the cut. Any woman who has not undergone female genital mutilation is referred to in derogatory terms. Therefore, when Ole Kaelo relocates from Nakuru (a town in present day Kenya) to Nasila with his two daughters (Taiyo and Resian) who are uncircumcised, the community chides them for keeping women who are beyond marriageable age in the homestead. In one incident when Taiyo and Resian step out for fresh air, they are accosted by a man who tells them that "soon, you will be able to differentiate decent women from Intoiye nemengalana! (Ole Kulet, p. 19). Intoiye nemengalana translates to 'a girl who has not been cut'.

In this case, any woman who is not circumcised is not "decent". To the two girls, this is a traumatizing encounter as they are ambushed with the culture that they have not been 
socialized into. They are therefore socially and psychologically traumatized yet they cannot confide in anyone. Though Mama Milanoi is aware of FGM as a cultural norm, she seems powerless and passive against the retrogressive traditional practice. According to tradition, no girl would be married without undergoing circumcision. As a mother, she does not know how to face up to male dominance and fight for the wellbeing of her daughters. As they relocate from Nakuru to Nasila, Taiyo and Resian are hit by the reality of Maasai traditions of female genital mutilation which is constantly looming over them. While in Nakuru, Taiyo and Resian were protected by Nakuru urban lifestyle against such practices. However, once in Nasila, they are powerless and exposed to all forms of indications that they have to undergo this rite of passage to be accepted as full members of the Maasai community.

In the novel, Yeiyo-bottor (the first wife of their elder uncle) is not happy with the way Resian and Taiyo were raised especially Resian's assertiveness. For instance, on one occasion, Resian complains about the gender disparity that requires women to toil and work nonstop to serve men while the men are just lazing around waiting for food. Resian questions such behaviour by pointing out that:

[D]o we go to all these lengths to please some lazy bunch of busybodies who do nothing but lounge about in the living rooms, yawning and stretching, waiting for tasty food to land on the table before them? No, I refuse to be taught to solely please male counterparts. (Ole Kulet, pp. 76-77)

Resian further argues that men "can also cook, and they can, and should also learn to please us females (Ole Kulet, p. 78). The quotation above captures the gender disparity in the Maasai culture. Resian's argument is an indictment of societal attitudes and behaviour that are employed to endorse sexist roles that discourage women from taking control or participating equally in more developmental oriented roles. For society to progress, both men and women have to work toward realizing such. The inclusivity of both men and women guarantees that the resourcefulness of each individual is tapped in the realization of development. Such development would be based on social and economic aspects of each person where each individual member is valued to have a stake in the progress of the society.

However, Mama Milanoi and Yeiyo-bottor are shocked about Resian's outburst and subversion of the Maasai culture that requires women to be submissive and silent. In order to nip such behaviour at the earliest, Yeiyo- bottor advices Mama Milanoi to have her daughters circumcised to get rid of olkuenyi (Ole Kulet, p. 78). Accordingly, Ole Supeyo observes that:

Female circumcision was not only an honoured rite of passage that had been in existence from time immemorial, but an important practice that tamed an otherwise wild gender. Like cattle that required to be dehorned, to reduce accidental injuries to each other, a certain measure of docility was also necessary [for women]. (Ole Kulet, p.22)

Ole Supeyo's sentiments above are not only dehumanizing but also devaluing women as human beings. By comparing women to cattle, Ole Supeyo demonstrates the low position occupied by women as he advocates for some docility. What we note here is that the concept of docility is advanced by men for their selfish gains and not for the benefit of women and society at large. In as much as culture advocates for FGM, it is silent on the impact that the same rite has on the victims. For instance, Taiyo recalls how she was forcefully circumcised that: 
She was dragged out, despite her fierce resistance. Once outside, about twenty litres of very cold water were emptied over her head. She shivered and tried to clear water from her eyes and ears but, strong hands held her and wrestled her to the ground. In the dim light of dawn, she saw the face of the enkamuratani [the circumciser] who she had once seen in their house at Nasila. She screamed and screamed, but nobody came to her rescue. Then she fainted. (Ole Kulet, p. 273)

It is instructive to point out that the quotation above paints a scary picture of how FGM is carried out. It is an act that not only leaves the physical scars of the cut but also psychological scars. The entire experience is beastly and barbaric given the pandemonium that accompanies the entire process as seen in Taiyo's case. What comes to the fore in this situation is lack of dignity and care in the whole process. As a result of this circumcision, we are told that Taiyo's health is greatly affected as she cannot even stand. She is emaciated to the core yet the adherents of the cultural practice are happy to have seen her through the rite at the expense of her health.

Unlike Taiyo who is forced to undergo the cut, Gathoni in Ngugi's The River between undergoes the female cut on her own volition because she wants to be a "real woman" in the tradition of her Gikuyu ancestors. Once circumcised, Gathoni feels complete, elated and no longer in conflict with her identity as a Gikuyu woman. However, she ends up succumbing to the circumcision wounds resulting from an infection. Whichever the case, whether forced or own will, female genital mutilation is risky as it places ones' life at stake.

Based on this, one can authoritatively observe that FGM is a health issue that may have far reaching and wide implications on the health sector and the well-being of the nation at large. If Taiyo had not been rescued in time by Minik, then her precious life would have been lost just like Gathoni's in the name of honouring outdated cultural practices. Taiyo points out that "it will take long before my conscience reconciles with what happened to me physically. The damage that was done to my mind, is indelibly printed on my memory" (Ole Kulet, p. 278). In this case, Taiyo is symbolic and representative of the many girls forcefully circumcised only to end up traumatized or even dying.

In the contemporary society, FGM should be shunned as it is a contributing factor to the destruction of young lives and potential. Resian and Taiyo represent many girls forced to undergo FGM to be married off. This rite of passage does not take into consideration the potential and development that girls can contribute to the society. For instance, Minik in Blossoms of the savannah is a woman who has a degree in Veterinary science from Makerere university. She is enlightened and has been single handedly fighting for an end to barbaric practices in her Maasai community. This has earned her loathing from her own people especially the die-hard implementors of such practices. Despite this, she has employed over 400 people from her community on her ranch. In doing this, those employed can earn an income and provide for their families. Therefore, if girls are allowed to follow their ambitions and aspirations, there is a likelihood of socio-economic development being felt in the immediate community and the country's gross domestic product (GDP).

Intertwined with female genital mutilation is the issue of early marriages. For one to get married, she has to undergo the cut. Of import in the text is the normalization and acceptance of marrying young and school going girls to old men. Early marriage refers to a union between two people in which one or both parties are younger than the legal age of consent. In 
some communities in Africa, early marriage of children is common. Some of such unions happen at birth when a child is booked by another family as either their wife or son-in-law. On early marriages, Resian asks "why is it that there is always a scramble for girls to marry in Nasila, to the extent that men are forced to book unborn baby girls and then they still have to wait for thirteen to fourteen years for them to mature?" (Ole Kulet, pp. 128-129). Though it is an acceptable traditional cultural practice within the mother community, the same is a violation of human rights and hinders any form advancement in the society.

Among the Maasai community, young girls are socialized into womanhood and prepared for marriage as early as possible. This is the problem when Resian and Taiyo are at their uncle's place because the relatives feel the girls were not prepared well. This is informed by their urban upbringing which did not socialize them in the ways of the community. As such, though belated, their culture has to be taught to them now that they are back in the village. One way of explaining the normalization of such practices is rooted in the manner in which boys and girls are viewed based on gender dichotomies. According to Parsons et al. (2015), early marriage is a practice deeply "rooted in gender inequality" (p. 12). In as much as the practice is cherished by the community, it greatly diminishes the early life of childhood and most importantly girlhood.

In this case, the girl child is not allowed to enjoy childhood and go through the different developmental stages as a child. Therefore, instead of being viewed as a girl child, she is ushered into the roles of a woman which blurs the lines between childhood and womanhood. The environmental shift from Nakuru to Nasila in Blossoms of the Savannah is a shift that brings the protagonists nearer to their origins and barbaric cultural practices. The bonding of the Ole Kaelos' to their origins aim at gaining an understanding of the Maasai culture which further contributes to the conflict in the narrative. For instance, after relocating to Nasila village, Ole Kaelo tells his wife (Mama Milanoi) that "you must immediately start counselling the girls to understand their roles as potential wives of the men of Nasila. Prepare them to appreciate and accept their future responsibilities as mothers and home builders" (Ole Kulet, p. 61). As a man and the head of his family, Ole Kaelo does not allow his wife to dialogue about his decision but that she should implement it to the letter. To Ole Kaelo, he does not see his daughters as children but potential wives to Nasila men.

Though early marriage is a source of pride to men and cultural adherents such as Yeiyo bottor in the Maasai culture, the same has profound effects on the child especially the girl child. For instance, the transition from childhood to adulthood is psychologically and physically challenging for young girls. The girl child loses her childhood as she is expected to assume marital roles. Therefore, socially, the girls are supposed to associate with girls their age not old men as husbands. In addition, since the girls are married off at a young age, there is a possibility of having too many children that they may not be able to cater for adequately and sometimes having high child mortality rates.

Therefore, having children that households cannot cater for their basic needs is a contributing factor to poverty. This has effects on individuals since the society is not in a position to develop economically and socially. Any progressive society should invest in its human resource. However, in the case of too many children, such a resource is wasted since such households and communities cannot compete with societies with a health human resource. Early marriage also has ripple effects on the welfare of families, and on society as a whole. 
This is because a sick family implies a sick community and a sick nation. For instance, when Resian is at Olarinkoi's homestead, she:

$[\mathrm{M}]$ et three young women who were married to old men twice or thrice their ages. One of them who was about eighteen, was married to an old man who was probably seventy-five years old. She was carrying a baby of six months or so and a boy of about four years tugged at her shukas. The children were constantly crying, a dreary monotonous tearless sob, with swarms of flies encircling their eyes and crowding their nostrils as they sucked the mucus that oozed from their noses. The other two women were younger. They were probably fifteen or sixteen, but they had all prematurely aged due to poor diet and hardships. (Ole Kulet, p. 239)

The excerpt above demonstrates the negative effects of early marriage. This could be explained as resulting from inadequate preparedness of becoming a mother and also as a result of the inability to cater for the basic needs for the family. In situations where girls are uninformed and ill-prepared as mothers, there is a likelihood to lead the type of lifestyle that is portrayed in the excerpt above. According to UNICEF (2001), "the immaturity and lack of education of a young mother undermines her capacity for nurture" (p. 11). The excerpt above demonstrates the inability of the girls to take care of themselves and family. It is also instructive to point out that as members of the society, girls are pivotal contributors to the wellbeing of the society.

Therefore, failure to give girls the necessary tools that would allow them take a stake in the development of the society leads to costs shouldered at every level of society beginning from the individual household to the nation as a whole. The sorry state of the family and society as illustrated in the depiction of the children with tearless cry and "the two women who are prematurely aged due to poor health and hardship" (Ole Kulet, p. 239) is a setback to development. A society with such individuals cannot progress since the resources that would otherwise be used to cater for development is diverted to taking care of such households.

Therefore, the image of the two women who have aged due to poor health shows how early marriage decreases a woman's early life and puts her at risky healthy issues. Accordingly, early marriage impedes her education which minimizes her economic opportunities. The inability of girls to pursue education increases chances of spousal violence as a result of financial dependency. Girls deserve full childhood experiences in life, go to school, be free from the violence and adverse outcomes associated with child marriage. Girls should also be allowed to choose when and who they are marrying for themselves without coercing and violence. In the text, girls are denied education since they have to be married off. When Taiyo and Resian move to Nasila village, people murmur since they are passed marriageable age yet they are still housed by their parents.

Though they had qualified to join Egerton University in present day Nakuru County in Kenya, this dream is threatened by the culture of their people. There is no indication that they are going to go back to school to realize their dreams. For instance, while in Nasila, Oloisudori, the chief financier of Ole Kaelo's business is interested in Resian. Since he is the financier of his business, Ole Kaelo agrees to Oloisudori's demands to marry Resian to him. The marriage of Resian to Oloisudori implies that Resian cannot continue with her studies but upon marriage, assume the responsibilities of a married woman. When Resian is informed about the marriage, she categorically tells her father that "if I don't die and I live to be eighty, 
I will still go to the university. I'll go to Egerton University Papaai, I tell you! I hope you will be there to witness my graduation (Ole Kulet, p. 210).

Resian's outburst is a reflection of her resilience and determination to quench her thirst for education. The inability of girls to pursue education has been explored by other African literary writers. For instance, Gicaamba in Ngugi wa Thiong'o's and Ngugi wa Mirii's I Will Marry When I Want succinctly points out that:

"We the parents have not put much effort in the education of our girls, we oppressed women, giving ourselvesnumerous justification ... forgetting that the home belongs to a man and woman, that a country belongs to boys and girls". (pp. 104-105)

Accordingly, in Dangarembga's Nervous conditions, Jeremiah tells his daughter (Tambu) that "can you cook books and feed them to your husband? Stay at home with your mother. Learn to cook and clean. Grow vegetables" (p. 15). Of note here is how most of the communities in Africa marginalize girls in matters of education. Access to education for both girls and boys is a basic human right yet the girl child is denied the same because of her biological make-up. In her lamentation about the impact of culture on its people, Taiyo declares that "I don't care about the oppressive Nasila culture. Why should I care about violating the backward culture when it does not care when it violates my own rights?" (Ole Kulet, pp. 132-133). Taiyo's outburst is a cry about the retrogressive practices that does not allow its people free will and human potential.

Education in the life of women is key to liberating them as it provides knowledge and raises awareness about the choices they make. I note that Nasila village is a strong patriarchal society where women are not allowed to make decisions, therefore opportunities such as education could avail such spaces for women to voice their thoughts. On the place of women in the Maasai community, Mama Milanoi observes that "in the Nasilian society, women had no say. It was a patriarchal society where the Emakererei and her ilk were fighting to find relevance with little success" (Ole Kulet, p. 62). The Emakererei referred to here is a woman called Minik Ene Nkoitoi, who had pursued her education at Makerere university and graduated with a degree in Veterinary Science. To the community, Minik is a bad woman and a bad example to young girls because she was fighting against traditional practices that she said abused girls' rights such as Female genital mutilation and girls' early marriage (Ole Kulet, p. 62).

Therefore, denying women access to education minimizes their economic prospects and resourcefulness. Women who are educated are likely to get employed as is the case of Minik. This then raises their chances of economic and financial stability which reduces their financial dependency on men. I note that women's financial stability leads to the realization of development in the immediate community and society at large. Therefore, the inability of girls to access education and better their livelihood has profound implications on the wellbeing and stability of the community and the society in general. For instance, through a stream of consciousness, Mama Milanoi wonders about whether in "embracing the retrogressive cultural values, were they now progressing or retrogressing?" (Ole Kulet, p. 62). From Mama Milanoi's stream of consciousness, she definitely knows that the community was retrogressing but deliberately invites readers to make an appropriate judgement on the impact of traditional practices on the society. 
There is also tension between formal and informal education in the text. For example, Joseph Parmuat, a primary school teacher in Nasila, was tasked to teach Taiyo and Resian traditional songs and dances instead of concepts in formal education. Resian is aware that her father was only interested in having them taught the Nasila culture but not take them to Egerton University. In her resentment about such a culture, Resian points out that:

[B]ecause we are females, a male in the name of a clan brother is sought to come along and teach us the ABCD of a good Nasilian wife so that we shall please our future husbands. No, I refuse to be taught. I will either be taught at the university what is universally beneficial to all mankind or to be taught nothing! (p. 75)

Resian further wonders "what would have happened had we been sons rather than daughters. Do you think father would have looked for a clan sister to coach us and take us through the dim cultural paths of Nasila? (Ole Kulet, p. 74). Resian represents the enlightened and knowledgeable women in the society. In raising such philosophical questions, Resian becomes aware of the limitation placed on her by her community. This is because she becomes conscious about the injustices perpetuated and justified through culture and its impact on her as a marginalized person. In this case, she is used deliberately in the text as an elite who has the vision of bringing change to her own community and the society in general.

On the place of education in the society, the narrative voice tells us that "in schools, the girls recalled learning that culture was the advance development of the human mind and body by training and experience (Ole Kulet, p. 150). This observation seems to be the script that informs Resian's behaviour. Therefore, Resian's observation in the quotation above is key in the realization of human potential since she wants to be taught what is universally beneficial to humankind. As such, she does not believe in being taught about the Nasila tradition that is not beneficial at all. Her argument is fundamental in the realization of development that is likely to impact society at the local and universal level. Therefore, if allowed to pursue education, it is likely to bring the desired change that the Maasai community needs. In this way, Resian is used as a mouthpiece by the writer to oppose and raise awareness about cultural practices that are not progressive. Resian is used symbolically to air her grievances from the disadvantaged position as a woman so as to challenge the customs that are detrimental to the progress of the community.

Through education, Taiyo and Resian had formed an identity or sense of self and those characteristics that a person wishes to have such as realizing their dreams. Taiyo and Resian had gotten formal education as opposed to the traditional informal education of their culture. Not only had they been taught, they had often mixed up with people from other cultures. As such, their behaviour is a mixture of the different cultures that they have interacted with. Their mother describes them negatively by saying that they were children of unknown origin, to discourage formal education. Education seems to be the only way through which women can be liberated and recreated in Blossoms of the Savannah. For instance, because of academic achievement, Minik finds the traditional practices inhumane and that is why she battles the society against female genital mutilation (FGM) and early marriages.

Another cultural practice that limits the development in this community is access of public and domestic spaces. Most women in Nasila are confined to the domestic space in their homes. The limitation of women to the domestic space curtails the realization of their 
potential as human beings. The confines of the home cannot provide appropriate knowledge and tools for women to engage in development related projects. This is because, within the home, women engage in jobs such as cooking, cleaning and reproducing children. Though such chores are essential within the home and for the welfare of the family, the same limits women from engaging in income generating ventures that are progressive in nature. The culture of curtailing women within the home cannot allow them to acquire other skills beyond the home. This in turn affects not only the social life of an individual but also the economic growth and development of the family and society.

Another anti-development cultural practice is the value placed on boys and girls. In most African communities and Maasai community in particular, boys are more valued than girls. A mother who has not given birth to boys is looked down upon and despised. For instance, in Blossoms of the Savannah, Parsimei Ole Kaelo wanted a boy after his firstborn daughter (Taiyo). In fact, he wished to have three boys and hoped that the second born would be a boy. However, he is disappointed when Resian-a daughter is born. We are told that:

When his wife became pregnant for the second time, he prayed for a healthy baby boy who would carry his name to the next generation. But that was not to be. Against his expectation, and to his utter disappointment, nature had given him another baby girl... he detested her. The very sight of her enraged him. (Ole Kulet, p.10)

And that:

He felt cheated by nature, for although it had been his prayer to get at least three boys, he had ended up with two girls. (Ole Kulet, p. 9)

The quotations above demonstrate the genesis of gender disparity which is pegged on the value of boys than girls. It is absurd that a father has to hate his own child because of sex. On gender disparity, Resian tells Taiyo that "I am beginning to think it is disadvantageous being a woman in this society (Ole Kulet, p. 74). As a child, Resian grows up knowing that her father hates her and this initiates her survival tactics and self-assertion. This is because as a girl child and an unwanted by the father, she had to fight her way in a society that did not value her as a human being. This hate made Resian suffer the whole of her life because her father's attitude toward her was an open secret. Resian grew up fearing her father. On one occasion, when she is clearing glasses from the table, her father enters the dining room and she became clumsy. Ole Kaelo is upset by her behavior and "wonders where in the world they fetched that awkward, overblown, stupid child. Her gracelessness appalled him. And the very look in her eyes, half-fearful, half-defiant and wholly troubled, was always enough to raise his temper to the highest pitch (Ole Kulet, pp. 40-41).

In this regard, Ole Kaelo's attitude towards his daughter affects her psychologically and even socially. As a child, she deserves affection and not the hatred that is openly displayed. Though this hatred is unhealthy, the same acts as a space within which Resian is propelled into agency. This is captured through her resilience and fighting spirit that eventually helps her free herself from the ensnaring cultural practices. 


\section{CONCLUSION}

This paper has examined the impact of traditional and cultural practices on the socioeconomic development in the Maasai community. The paper examined early marriage, female genital mutilation, girls' education, gender disparity, domestic and public spaces and how the same work against the socio-economic development. The discriminative traditions and customs advance social, cultural and economic inequality in the society as they eventually lead to stagnation in matters of development. The paper established that the most traditional practices among the Maasai community are retrogressive, inhuman and lack value in the contemporary $21^{\text {st }}$ century society.

\section{REFERENCE}

Aziza, R.C. (2001). "The Relationship between Language use and Survival of Culture: The Case of Umobo youth". Nigerian Language Studies. No.4.

Bello, S. (1991). Culture and Decision Making in Nigeria. Lagos: National Council for Arts and Culture.

Ole-Kulet, H. R. (2008). Blossoms of the Savannah. Nairobi: Sasa sema publishers.

Parsons, J., Edmeades, J., Kes, A., Petroni, S., Sexton, M., \& Wodon, Q. (2015). Economic impacts of child marriage: A Review of the literature. In The Review of Faith \& International Affairs, Vol. 13, Issue 3.

Tsitsi, D. (1989). Nervous conditions. Zimbabwe publishing house

UNICEF (March, 2001). Early Marriage: Child spouses. Innocenti Digest no. 7. Available at: impact $\% 20$ of\%20early\%20marriages.pdf

Wa Thiong;o, N. (1965). The River between. Nairobi: Heinemann.

Wa Thiong'o, N., \& Wa Mirii, N. (1977). I will marry when I want. London: Heinemann. 